\title{
PUBLIC ECOLOGICAL ORGANIZATIONS OF THE VOLGA REGION AND THEIR RELATIONS WITH THE GOVERNMENT IN 1980-1990
}

(C) 2019

Makeeva Ekaterina Dmitrievna, candidate of historical sciences, associate professor of Physics, Mathematics and Teaching Methods Department Samara State University of Social Sciences and Education (Samara, Russian Federation)

Abstract. In 1980-1990 in the Soviet Union the activity of nature protection movement has sharply increased against processes of society democratization and considerable deterioration of ecological conditions. A considerable number of various public ecological organizations were established; they tried to adjust dialogue with the government and actively involved the population in sociopolitical life of the country. The following paper considers contribution to ecological movement development in the cities of the Middle and the Lower Volga Region where the public fought against the policy of nature management directed first of all on satisfaction of the USSR economic departments interests as well as against inability of the authorities to solve local problems of environment protection effectively. The author considers most widespread forms of the public ecological organizations activity, analyzes their relations with the local and regional authorities in dynamics. The paper also contains examples of interactions of the government and the public when solving nature protection problems. Studying the experience of the Volga Region ecological movement activity can promote making positive relations of ecologists with representatives of the government in modern Russia that finally will allow to improve the general nature protection situation in the country.

Keywords: ecological movement; Middle and Lower Volga Region; environment protection; Perestroika meetings; protest movement in USSR; public ecological organizations; civil society; relations of government with society; «green» movement.

УДК 94

DOI 10.24411/2309-4370-2019-11214

Статья поступила в редакцию 20.12.2018

\section{СТРАТЕГИЯ «РАСПРОСТРАНЕНИЯ ДЕМОКРАТИИ» КАК МЕХАНИЗМ ДОСТИЖЕНИЯ АМЕРИКАНСКИХ ВНЕШНЕПОЛИТИЧЕСКИХ ЦЕЛЕЙ (КОНЕЦ 1980-Х - ПЕРВАЯ ПОЛОВИНА 1990-Х ГГ.)}

(C) 2019

Белевцева Светлана Николаевна, кандидат исторических наук, доцент кафедры всеобщей истории Курский государственный университет (2. Курск, Российская Федераиия)

Аннотаџия. В статье рассматриваются вопросы реализации внешней политики США в период президентства Дж. Буша-старшего и первого президентского срока Б. Клинтона. Анализируются практические шаги американской администрации, связанные с применением стратегии «распространения демократии» как одного из основных инструментов американской внешнеполитической деятельности. Прослеживается использование стратегии «распространения демократии» для целей достижения американского глобального лидерства в условиях становления однополярного мира. Показано влияние на формирование внешней политики США прецедента - отсутствия сдерживающего фактора в лице СССР. Отдельное внимание уделено продвижению демократии американского образца в регионы мира, в которых возникали конфликтные ситуации. Приведены факты обоснований американским истеблишментом необходимости американского лидерства в международных делах. Дана оценка преемственности во внешней политике США силового давления под лозунгом «распространения демократии». Статья основана на документальных материалах президентов США Дж. Буша-старшего и Б. Клинтона, а также документах Государственного департамента и Конгресса США. Для оценки деятельности американских администраций использованы мнения видного американского политолога Генри Киссинджера, президента американского Института экономической стратегии Клайда Престовица и российского историка В.В. Согрина.

Ключевые слова: стратегия «распространения демократии»; американское глобальное лидерство; региональные конфликты; политика силового давления; СССР как сдерживающий фактор; преемственность американской внешней политики; необходимость изменений в американской внешней политике; несоответствие идей и практики внешней политики США.

Джордж Герберт Уокер Буш (Дж. Буш-старший), имевший значительный опыт внешнеполитической, в том числе дипломатической, работы, а также в течение восьми лет исполнявший обязанности вицепрезидента США, по всем оценкам, вошёл в Белый дом как опытный политик. В своей внешнеполитической деятельности он продолжил курс Р. Рейгана, использовавшего стратегию «распространения демократии» как средство «вытеснения коммунистиче- ской идеологии и утверждения американского влияния» [1, с. 50] в мире.

Уильям Джефферсон (Билл) Клинтон, напротив, считавшийся несведущим в международных делах и победивший Дж. Буша-старшего на президентских выборах 1992 г., убедив американцев в необходимости работы в первую очередь над внутренними проблемами Америки, тем не менее принял эстафету продвижения американской демократии в различные 
регионы мира и сделал это направление своей внешней политики главенствующим. Невозможно однозначно причислить к успеху боевые действия США в Боснии (1995) или не признать провальными действия американских военных в Сомали (1993). Однако в конечном счёте главная цель американской внешней политики, заключавшаяся в утверждении однополярного мира во главе с США, к середине 1990-х годов была достигнута.

\section{Стратегия «распространения демократии»}

\section{как средство утверждения}

американского лидерства

В начале 1989 года, когда Дж. Буш-старший сформировал новую президентскую администрацию, положение Соединённых Штатов на международной арене уже можно было считать исключительным. Советский Союз практически отказался от построения коммунизма и исповедовал новое политическое мышление, направленное на демократизацию своего общественного строя. В конце января 1989 г. в Сенате Конгресса США прозвучало заявление Чака Грассли о том, что «Советы продемонстрировали значительный прогресс: эмиграция является самой высокой с конца 1970-х годов. И за последние 2 года были освобождены сотни политзаключенных. На данный момент, похоже, гласность и перестройка Генерального секретаря Горбачева изменили ситуацию» [2, p. S814]. А через несколько дней в Палате представителей прозвучало заявление о том, что предоставление советским гражданам возможности эмиграции из страны позволит «отказаться от ограничений поправки Джексона-Вэника на первоначальный восемнадцатимесячный период» [3, p. Н533].

В сложившихся условиях, как отмечал в своей книге «Дипломатия» Генри Киссинджер, «конец "холодной войны" породил ... искушение переделать мир по американскому образу и подобию» [4, с. 733]. Позднее Киссинджер более детально исследовал и описал американское видение внешней политики на рубеже 1980-х - 1990-х гг. Он, в частности, отмечал: «Победа в "холодной войне" искушала самодовольством; удовлетворённость сложившимся status quo побуждала проецировать на будущее текущую политику; впечатляющие экономические успехи давали политическим лидерам соблазн смешивать стратегическое мышление с экономическим... Совпавшее по времени с окончанием "холодной войны" это сочетание самодовольства и процветания породило ощущение особой "американской миссии", выразившееся в двойном мифе. $B$ cmaне левых многие увидели в Соединённых Штатах главного арбитра по внутриполитическим вопросам во всём мире. <..> Среди npaвblx некоторые полагают, будто крах Советского Союза произошёл в значительной мере автоматически... а не вследствие полувековых усилий девяти последних администраций» [5, с. 3-4].

Таким образом, вмешательство во внутренние дела других государств для большинства представителей всех ветвей власти США стало нормой. А стремление демократизировать весь мир стало стратегическим направлением американской внешней политики. Уже на первом заседании Сената 101 Конгресса США из уст нового лидера демократического большинства, сенатора Джорджа Митчелла, прозвучало заявление: «Наши идеалы и наши собственные инте- ресы требуют сильной и устойчивой американской поддержки свободы и демократических ценностей во всем мире» [6].

При этом администрация Дж. Буша-старшего, получившая как наследие от Р. Рейгана новые отношения с Советским Союзом - страной, отказавшейся от политики применения военной силы в международных делах и стремившейся к дружбе с США, - не считала обязательным вести себя на международной арене таким же образом. Напротив, потеря сдерживающего фактора в лице СССР позволяла Соединённым Штатам применять силу, в том числе военную, при решении региональных проблем, без прежней оглядки на бывшего идеологического и военнополитического соперника.

Генри Киссинджер, говоря о внешней политике начала 1990-х гг., отмечал достаточно поверхностную оценку Дж. Бушем-старшим (как и его преемником Б. Клинтоном) складывающегося нового мирового порядка (хотя сами президенты на этот счёт явно были другого мнения). По мнению мэтра американской политологии, президенты принимали изменения в расстановке сил на мировой арене как свершившийся факт и не предполагали, что именно в этот период необходимо было вносить изменения во внешнюю политику США. Сам же Киссинджер полагал: «Будучи частично продолжением прошлого, а частично беспрецедентным, новый мировой порядок, как и те, на чьё место он приходит, должен возникнуть как ответ на три вопроса. Что является фундаментальными составляющими мирового порядка? Каковы способы их взаимодействия? Каковы цели, ради которых происходит подобное взаимодействие?» $[4$, с. 734]. Постановка этих вопросов в 1994 году была, скорее, ответом Киссинджера на прямолинейную внешнюю политику США, политику, определяемую открывшимися никем и ничем не сдерживаемыми возможностями, начало которой положила администрация Дж. Буша-старшего после победы над коммунизмом в Восточной Европе и многих государствах третьего мира, а также распада СССР.

При этом Дж. Буш-старший так оценивал международную ситуацию начала 1989 года: «... мир представлял собой знакомую биполярную модель соперничавших сверхдержав, хотя это соперничество уже не было тотальной конфронтацией» [7, с. 12-13]. Отсутствие конфронтации с СССР позволяло США повсеместно внедрять западные, преимущественно американские, принципы демократии. Уже в своей инаугурационной речи Дж. Буш-старший утверждал: «Впервые в этом столетии, впервые за всю историю, человек не должен изобретать систему, с помощью которой можно жить» [6]. Президент США был убеждён в необходимости насаждения демократических форм правления по всему миру. А использование силы для этих целей становилось нормой. В начале своей инаугурационной речи Дж. Буш-старший произнёс молитву по этому поводу. «Небесный Отец, мы склоняем головы и благодарим тебя за твою любовь. Прими нашу благодарность за мир, который приносит этот день, и общую веру, которая делает возможным его продолжение. Сделай нас сильными, чтобы мы делали твою работу, желающими внимать и слышать твою волю, и напиши в наших сердцах такие слова: "используй силу, чтобы помогать лю- 
дям"» [6], - эти молитвенные слова отразили стремление новой американской администрации к череде силовых внешнеполитических действий. При этом Соединённые Штаты использовали как рычаги экономического давления и гуманитарные интервенции, так и открытое применение военной силы.

В период президентства Дж. Буша-старшего ещё не прозвучало предостережение Г. Киссинджера относительно региональной политики США. Но вооружённое вмешательство в различные конфликты в конце 1980-х - начале 1990-х гг. позволило, с учётом прочих аргументов, сделать американскому политологу вывод о том, что «по ходу времени Соединённые Штаты лишатся части своей исключительности. В обозримом будущем у американской военной мощи по-прежнему соперников не будет. И всё же американское стремление направить эту мощь на мириады крохотных конфликтов, которым мир явится свидетелем в течение надвигающихся десятилетий типа Боснии, Сомали и Гаити, - явится ключевым концептуальным вызовом для американской внешней политики» [4, с. 737].

Нельзя сказать, что вызовов, по собственной оценке американцев, не существовало в период президентства Дж. Буша-старшего. Можно лишь утверждать, что не существовало угроз собственно Соединённым Штатам. И если в круг угроз национальной безопасности добавить безопасность союзников, безопасность тех государств, для которых «норвежский исследователь Г. Лундестад, анализируя это явление, счёл возможным назвать США "империей по приглашению"» $[8$, с. 24], и тем более добавить интересы США на мировой арене, то вызовы, несомненно, были. Эти вызовы вносили коррективы скорее в тактику поведения США в международных делах, но не меняли стратегической линии на мировое господство.

Сущность и цели внешнеполитической стратегии Соединенных Штатов при президенте Дж. Бушестаршем оставались традиционными, но преподносились более безапелляционно, в соответствии с новым раскладом сил в мировой политике. При этом генеральная линия на завоевание лидирующих позиций в мире с применением стратегии «распространения демократии» оставалась неизменной.

Выдвижение проблемы региональных конфликтов в ранг важнейших внешнеполитических задач США в период президентства Дж. Буша-старшего

Изменение международной ситуации повлияло на стратегические цели США во внешней политике и методы их достижения. В мире, где советская военная угроза перестала быть обоснованием для поддержания военной мощи США как внутри страны, так и в среде ближайших союзников, региональная нестабильность стала новым фактором, требующим усиления вооружённых сил США и их присутствия в различных уголках планеты. В докладе Белого дома «Стратегия национальной безопасности Соединённых Штатов», подписанном президентом Дж. Бушем-старшим в августе 1991 г., говорилось: «Как ясно показала война в Персидском заливе, ослабление советской угрозы не означает прекращения всех опасностей. Стремясь построить новый мировой порядок после окончания холодной войны, мы, вероятно, обнаружим, что враг, с которым мы сталкиваемся, не столько экспансионистский коммунизм, сколько нестабильность. И перед лицом многочисленных и разнообразных угроз стабильности мы всё чаще будем считать нашу военную мощь источником уверенности и основой безопасности на региональном и глобальном уровнях» [9].

При этом в докладе обосновывалась необходимость американского вмешательства в региональные дела и указывалось на ожидаемый эффект от подобных американских действий. «Сохранение позитивного влияния в отдаленных регионах требует от нас демонстрации нашей вовлечённости, - говорилось в докладе. - Наше присутствие может сдерживать агрессию, сохранять региональный баланс, отводить гонку вооружений и предотвращать вакуум власти, порождающий конфликты» [9, р. 27]. Делался вывод о выдвижении региональных конфликтов в число первоочередных внешнеполитических задач, о чём в докладе говорилось следующее: «Поскольку региональные кризисы являются преобладающей военной угрозой, с которой мы столкнёмся в будущем, связанные с ними требования, наряду с нашими требованиями о передовом присутствии, будут главным фактором, определяющим размеры и структуру наших будущих сил» $[9$, р. 28]. Вместе с тем, понимая, что в мире после окончания холодной войны «международные отношения обещают быть более сложными, более изменчивыми и менее предсказуемыми» $[9$, р. 2], в докладе определена четвёрка фундаментальных для США стратегических целей: «обеспечение стратегического сдерживания, осуществление передового присутствия в ключевых регионах, эффективное реагирование на кризисы и сохранение национального потенциала по восстановлению сил до необходимого уровня» [9, р. 25].

Тактика достижения указанных внешнеполитических целей, как и прежде, основывалась на принципах «распространения демократии» по всему миру. При этом в докладе о «Стратегии национальной безопасности Соединённых Штатов» 1991 года в очередной раз увязывались вопросы оказания экономической помощи с демократическими преобразованиями в государствах - претендентах на такую помощь. В частности, в докладе говорилось: «Наши программы [экономические] будут становиться всё более ценным инструментом для определения политического выбора, прав человека и самоопределения. От Центральной Америки до Южной Африки и Восточной Европы мы использовали наше влияние для достижения этих целей» [9, р. 17]. К 1991 году это влияние через экономическую помощь в обмен на демократизацию внутриполитической жизни было действительно успешным.

Однако экономическая помощь не всегда оказывалась эффективной с точки зрения достижения американских внешнеполитических целей. А вот применение военной силы чаще всего давало результат ожидаемый и оперативный. В данном контексте звучали заявления представителей администрации Дж. Буша-старшего. В частности, госсекретарь США Дж. Бейкер рассматривал «американское участие в урегулировании региональных конфликтов в качестве составной части создания безопасных военнополитических условий для развития демократии и рыночной экономики» [10, р. 5].

В качестве средства урегулирования региональных конфликтов и достижения американских внеш- 
неполитических целей администрация Дж. Бушастаршего разработала концепцию так называемых «свободных и честных многопартийных выборов» как основы «национального примирения» [10, р. 5]. Эта концепция была задействована Соединёнными Штатами в различных уголках планеты, от ближайших стран Латинской Америки до государств Европы, Азии и Африки.

\section{Политика администрации Б. Клинтона}

в отношении региональных конфликтов

в контексте «распространения демократии»

Для администрации Б. Клинтона, пришедшей к руководству в январе 1993 года, как и для их предшественников, региональные конфликты по всему миру - как внутригосударственные, так и межгосударственные - служили поводом для вмешателства с целью реализации своих национальных интересов. Для США не имело особого значения, из-за чего разгорелся конфликт, главным было урегулировать его (а в каких-то случаях и не спешить с этим) на условиях, выгодных для Америки. При этом США либо занимали позицию той стороны, которая была ближе американскому менталитету (возвращение президента Жан-Бертрана Аристида на Гаити), либо Соединённые Штаты поддерживали тех, кто был готов идти навстречу американским требованиям (хорваты, боснийские мусульмане в бывшей Югославии), либо США просто провоцировали ситуацию для оправдания своего вмешательства (действия в Ираке) [11]. При этом применение военной силы в первой половине 1990-х гг. уже не являлось запретным, требующим согласования или одобрения мирового сообщества. Точнее, усилия по «сохранению лица» предпринимались, но, если американские планы отвергались, США действовали без разрешения ООН или одобрения НАТО.

К началу 1993 года в американском истеблишменте практически не оставалось сомневающихся в необходимости для США взять на себя лидерские функции в любых международных делах. На первом заседании Палаты представителей 103 Конгресса конгрессмен от штата Джорджия Ньют Гингрич заявлял: «На карту поставлено будущее свободы. Без Америки будет больше Босний, больше Сомали, больше Ираков. Мы единственная страна, достаточно большая, достаточно сложная, достаточно многорасовая, чтобы действительно обеспечить лидерство для свободы по всей планете. Если мы ослабеем, если мы потеряем нашу волю, если мы потеряем нашу экономическую мощь, если мы потеряем наш потенциал, нас некому будет заменить» [12].

При этом, по мнению президента Клинтона, «Америка, применив силу, могла остановить государства, непосредственно связанные с направленной против неё террористической деятельностью» [13, c. 804].

Б. Клинтон, будучи убеждённым, что «Америка должна продолжать лидировать в мире» [14], уже в своей первой инаугурационной речи заявил: «Когда наши жизненно важные интересы ставятся под сомнение или когда игнорируются воля и совесть международного сообщества, мы будем действовать мирной дипломатией, когда это возможно, и силой, когда это необходимо» [14]. Таким образом, его ад- министрация нацеливалась на достижение целей американской внешней политики любыми средствами, доступными США.

Вместе с тем, объективно оценивая изменения внешнеполитической обстановки, готовившийся к вступлению в должность Государственного секретаря США Уоррен Кристофер, выступая в Конгрессе, отмечал: «... наша администрация наследует задачу определения стратегии для руководства США после холодной войны. Мы не можем позволить себе переходить от кризиса к кризису. Мы должны иметь новую дипломатию, которая стремится предвидеть и предотвращать кризисы, как в Ираке, Боснии и Сомали, а не просто управлять ими. Наша поддержка демократических институтов и прав человека может помочь разрядить политические конфликты» [15, p. 46]. При этом У. Кристофер указывал на необходимость изменения трактовки целей американской внешней политики. По его мнению, «единственная цель сдерживания советской силы должна быть заменена более сложным обоснованием для новой эпохи. Мы должны показать, что в эту эпоху внешняя политика больше не является внешней. Практики государственного управления иногда забывают, что их конечная цель - улучшить повседневную жизнь американского народа» $[15$, р. 46].

Таким образом, теоретически обосновывалась необходимость гегемонии США. Однако благие цели улушения жизни американцев оставляли цели других народов вторичными, подчинёнными интересам Coединённых Штатов. В связи с этим справедливо мнение Клайда Престовица, президента американского Института экономической стратегии: «В то время как весь мир внимательно наблюдает за Америкой и считается с её мнением, самим американцам часто невдомёк, что могут существовать иные мнения, либо этими мнениями американцы просто пренебрегают» [16, с. 29].

На условиях американской гегемонии администрация Б. Клинтона стремилась расширить сообщество демократических государств. Принятая в середине первого президентского срока Б. Клинтона новая «Стратегия национальной безопасности США. Стратегия вовлеченности в международные дела и распространение демократии в мире» [17] предусматривала отход от изжившей себя политики сдерживания СССР и сосредоточении на расширении «числа демократических государств с рыночной экономикой» $[18$, с. 117]. Стратегия национальной безопасности Б. Клинтона, получившая краткое наименование «от сдерживания к расширению», провозглашала: «Суть нашей стратегии заключается в содействии демократии, расширении рынков и сохранении наших позиций в регионах, вызывающих наибольшую озабоченность с точки зрения безопасности и в которых мы можем достичь наибольших результатов. Это не крестовый поход для установления демократии. Это прагматическая политика для поддержания свободы там, где она будет в наибольшей степени соответствовать интересам США» $[18$, c. 117].

Именно так и формировался внешнеполитический курс первой администрации Б. Клинтона. Интересы США, а не что-то другое были целью американской внешней политики. Стратегия «распростра- 
нения демократии» служила лишь механизмом достижения американских целей, а в ряде случаев просто декларацией для прикрытия экспансионистских действий.

Несмотря на заявления о стремлении к разрядке в международных и внутригосударственных конфликтах, Соединённые Штаты использовали весь арсенал силового воздействия для создания в регионах мира структур, не просто миролюбивых, но обеспечивающих процветание США и закрепляющих за ними статус единственной сверхдержавы.

Практика внешнеполитических действий первой администрации Б. Клинтона отличалась от провозглашённого У. Кристофером стремления «предвидеть и предотвращать кризисы». В период первого президентства Б. Клинтона США продолжали военные операции, начатые предыдущей администрацией, в Ираке и Сомали. Защищали свои национальные интересы на Гаити, хотя с этого островного государства им никто и ничто не угрожало. При этом первая демонстрация военной силы у берегов Гаити была проведена без санкции ООН. В Боснии и Герцоговине США совместно с партнёрами по НАТО провели воздушные и наземные боевые операции против сербов, которых заранее назначили виновными за боснийскую резню. И в этом случае США долго убеждали партнёров по НАТО в необходимости вооружённого вмешательства в боснийскую войну [19].

Вместе с тем вновь в противовес заявлению У. Кристофера о том, что американская «поддержка демократических институтов и прав человека может помочь разрядить политические конфликты», США проигнорировали призывы о защите населения Руанды, подвергшегося геноциду со стороны собственного правительства. И объяснялось это отсутствием значимых интересов США в этом регионе. Как указывал российский исследователь Д.В. Кузнецов, «гибель сотен тысяч человек из числа руандийцев вызывала сочувствие среди американцев, но жертвовать жизнями американских военнослужащих ради спасения погибающих африканцев они, и это также достаточно очевидно, не были готовы» [20, с. 141].

\section{Преемственность политики}

силового давления

Процесс «распространения демократии» в период президентства Дж. Буша-старшего традиционно служил продвижению интересов Соединённых Штатов на международной арене. В конце 1980-х - начале 1990-х гг. лидерские позиции позволяли США проводить внешнюю политику без оглядки на других акторов международных отношений.

Применение силы, сделавшись нормой американской внешней политики, оправдывалось большинством американского истеблишмента в период президентства Дж. Буша-старшего и было подхвачено новой администрацией Б. Клинтона.

Дж. Буш-старший, уже проиграв очередные президентские выборы, в одном из своих последних выступлений, адресованном слушателям военной академии в Вест-Пойнте, так оценивал международную обстановку и цели американской внешней политики: «Хотел бы я сказать... что с окончанием холодной войны призывы к Соединенным Штатам уменьшатся. Не могу. Да, окончание холодной войны, мы все признаём, это благословение. Это время больших надежд. Демократические правительства никогда не были столь многочисленны. <...> Но это не значит, что нет призрака войны, нет угроз, с которыми нужно считаться. И уже сейчас мы видим тревожные признаки того, каким может стать этот новый мир, если мы будем пассивными и отчуждёнными» [21].

Такое «политическое завещание» 41-го президента США было востребовано и президентом Биллом Клинтоном. Его Госсекретарь Уоррен Кристофер при вступлении в должность отмечал: «Несмотря на смену администрации, наша политика во многих конкретных случаях будет оставаться неизменной и будет стремиться опираться на достижения наших предшественников» $[15$, p. 46]. А характеризуя внешнюю политику, он назвал три её основные цели, указанные президентом Клинтоном: «Во-первых, мы должны повысить экономическую безопасность Америки в качестве главной цели нашей внешней политики. Во-вторых, мы должны сохранить нашу военную мощь по мере адаптации наших сил к новым вызовам безопасности. В-третьих, мы должны организовать нашу внешнюю политику вокруг задач содействия расширению демократии и рынков за рубежом» $[15$, p. 46].

Таким образом, знамя демократии было не просто передано из рук Дж. Буша-старшего Б. Клинтону, но и поднято клинтоновской администрацией на новую высоту. Ни первая, ни вторая администрации Б. Клинтона не ставили задачи демократизации всего мира, но существенно расширить круг демократий они стремились. При этом программа «от сдерживания к расширению» была нацелена не просто на увеличение количества стран с демократической формой правления. Целью было «распространение демократии» американского образца, демократии, признающей главенствующую роль США в международных делах. По сути, эти цели, обеспечивающие Соединённым Штатам главенствующее положение в мировом сообществе, актуальны и в настоящее время. И процветание США создаётся и гарантируется благодаря именно этому их статусу.

\section{Список литературы:}

1. Белевцева С.Н. Реализация американской стратегии «распространения демократии» посредством урегулирования региональных конфликтов в период второго президентского срока Р. Рейгана // Известия Саратовского университета. Новая серия. Серия История. Международные отношения. 2013. Т. 13. Вып. 3. С. 49-56.

2. Helsinki Commission Codel to U.S.S.R. (Senate January 31, 1989) // Congressional Record 101st. S. 814.

3. Continue the Dialog on United States/Soviet Trade (House of Representatives - March 06, 1989 // Congressional Record 101st. H. 533.

4. Киссинджер Г. Дипломатия. М.: Ладомир, 1997. 848 c.

5. Киссинджер Г. Нужна ли Америке внешняя политика? М.: Ладомир, 2002. 352 с.

6. Constitutional Compromise (Senate - January 25, 1989) // Congressional Record 101st. S. 88.

7. Буш Дж., Скоукрофт Б. Мир стал другим. М.: Междунар. отношения, 2004. 504 с. 
8. Согрин В.В. США в XX-XXI веках. Либерализм. Демократия. Империя. М.: Издательство «Весь Мир», 2015. 592 c.

9. Inaugural Address. January 20, 1993 // Public Papers of the Presidents of the United States: William J. Clinton (1993, Book I). P. 2.

10. Baker J. U.S. Foreign Policy Priorities and Fiscal Year 1991 Budget Request. Statement by Secretary of State. 1 Febr. 1990 // American Foreign Policy. Current Documents. 1990. U.S. Department of State. Wash., 1991. P. 5.

11. Белевцева С.Н. Силовое продвижение американской демократии в регионы мира в период первого президентского срока Билла Клинтона // Ученые записки. Электронный научный журнал Курского государственного университета. 2018. № 3 (47). C. $68-82$.

12. Renewing American Civilization (House of Representatives - January 25, 1993) // Congressional Record 103rd. H. 197.

13. Клинтон У.Дж. Моя жизнь. М.: Альпина Бизнес Букс, 2005. 1088 с.

14. Inaugural Address. 20.01.1989 [El. resourse] // Public Papers. George Bush Presidential Library and Museum. - https://bush41library.tamu.edu/archives/publicpapers/1.

15. Statement at Senate Confirmation Hearing. Secretary-Designate Christopher. Statement before the Sen- ate Foreign Relations Committee, Washington, DC, January 13, 1993 // US Department of State Dispatch. Bureau of Public Affairs. January 25, 1993. Wash., DC: US GPO. Vol. 4, № 4. P. 46.

16. Престовиц К. Страна-изгой. Односторонняя полнота Америки и крах благих намерений. СПб.: Амфора. ТИД Амфора, 2005. 606 c.

17. Стратегия национальной безопасности США. Стратегия вовлеченности в международные дела и распространение демократии в мире // США - Канада: экономика, политика, идеология. 1994. №№ 11, 12; 1995. №oo $1,2$.

18. Стратегия национальной безопасности США. Стратегия вовлеченности в международные дела и распространение демократии в мире (окончание) // США - Канада: экономика, политика, идеология. 1995. № 2. C. 112-126.

19. National Security Strategy of the United States. The White House, Washington, DC, 1991. P. 25.

20. Кузнецов Д.В. Американское общественное мнение и использование военной силы: Период президентства Уильяма Дж. Клинтона (1993-2001 гг.). М.: Книжный дом «ЛИБРОКОМ», 2011.304 c.

21. Remarks at the United States Military Academy in West Point, New York. 05.01.1993 // Public Papers. George Bush Presidential Library and Museum. https://bush41library.tamu.edu/archives/publicpapers $/ 5156$

\section{«DEMOCRACY DISTRIBUTION» STRATEGY AS A MECHANISM FOR U.S. FOREIGN POLICY GOALS ACHIEVING (LATE 1980S - FIRST HALF OF THE 1990S)}

(C) 2019

Belevtseva Svetlana Nikolaevna, candidate of historical sciences, associate professor of World History Department Kursk State University (Kursk, Russian Federation)

Abstract. The paper deals with the US foreign policy during the presidency of George W. Bush and B. Clinton's first presidential term. The author analyzes practical steps of the American administration related to the use of «democracy distribution» strategy as one of the main tools of the American foreign policy. The paper traces the use of «democracy distribution» strategy for the purpose of American global leadership achieving in the conditions of the unipolar world. The author also shows the influence on the US foreign policy precedent creation - lack of deterrent in the face of the USSR. Special attention is paid to the promotion of American-style democracy to the regions of the world where conflict situations arose. The paper also contains the facts that the American establishment justified the necessity of American leadership in international affairs as well as the assessments of the US foreign policy of power pressure under the slogan of «democracy distribution». The paper is based on the documentary materials of the US presidents G.W. Bush and B. Clinton, as well as documents of the U.S. Department of state and Congress. The views of prominent American political scientist Henry Kissinger, President of the American economic strategy Institute Clyde Prestowitz and Russian historian Vladimir Sogrin are used to assess the activities of the American administrations.

Keywords: «democracy distribution» strategy; American global leadership; regional conflicts; policy of power pressure; USSR as deterrent; continuity of American foreign policy; need for changes in American foreign policy; inconsistency of ideas and practices of US foreign policy.

УДК 93/94

DOI 10.24411/2309-4370-2019-11215

Статья поступила в редакцию 11.01.2019

\section{ЯПОНСКАЯ КОЛЛЕКЦИЯ В.В. ВЕРЕЩАГИНА: ВОПРОСЫ, ОТВЕТЫ, ЗАГАДКИ}

(C) 2019

Кацнельсон Галина Сергеевна, кандидат исторических наук, преподаватель лицея Национальный исследовательский университет «Высшая школа экономики» (г. Москва, Российская Федерация)

Аннотащия. В данной статье рассматривается коллекция японских произведений искусства, которые были приобретены известным российским художником В.В. Верещагиным в ходе его путешествия в Японию в 1903 г. В статье представлена основная информация о самом путешествии, приводятся выдержки из заметок Верещагина о стране и интересующих его произведениях искусства, которые он покупал. Описание коллек- 